\title{
Haemostatic and haemodynamic abnormalities associated with left atrial thrombosis in non-rheumatic atrial fibrillation
}

\author{
R M Heppell, K E Berkin, J M McLenachan, J A Davies
}

\begin{abstract}
Objective-To evaluate the role of haemostatic and haemodynamic variables in left atrial thrombosis in non-rheumatic atrial fibrillation.

Design-Case-control study.

Subjects-One hundred and nine patients with non-rheumatic atrial fibrillation.

Interventions-Peak blood velocity measured at three sites in the left atrium. Venous blood sampled for coagulant proteins and markers of haemostatic activation.
\end{abstract}

Main outcome measures-Presence of left atrial thrombus and spontaneous echo contrast at transoesophageal echocardiography.

Results-Left atrial thrombus was identified in 19 patients (18\%), 16 of whom had spontaneous echo contrast. Patients with thrombus had reduced peak left atrial appendage velocity compared with those without $(0.17 v 0.26 \mathrm{~m} / \mathrm{s} ; \mathrm{P}<0.001)$, but no significant reductions in peak mid-left atrial or mitral valve outflow velocity. Patients with thrombus had increased plasma markers of platelet activation- $\beta$ thromboglobulin $(56.8 v 30.4 \mathrm{IU} / \mathrm{ml} ; P<$ $0.001)$ and platelet factor $4(6.1 v 3.5$ IU/ml; P < 0.01) -and of thrombogenesis: thrombin-antithrombin complexes $(5 \cdot 59$ v $3.06 \mu \mathrm{g} / \mathrm{ml} ; \quad P<0.001)$ and $D$-dimers (479 v $298 \mathrm{ng} / \mathrm{ml} ; \quad P<0.01$ ). von Willebrand factor was also increased (1.81 $v 1.52 \mathrm{IU} / \mathrm{ml} ; \mathbf{P}<0.05)$. A multiple logistic regression model identified left atrial appendage velocity $(P=0 \cdot 001), \beta$ thromboglobulin $(P=0.002)$, and von Willebrand factor $(P=0.04)$ as the independent associates of left atrial thrombosis, ahead of the presence of spontaneous echo contrast.

Division of Medicine University of Leeds, Leeds, United

Kingdom

R M Heppell

J A Davies

Department of Cardiology, The

General Infirmary,

Leeds, United

Kingdom

KE Berkin

J M McLenachan

Correspondence to:

Dr R M Heppell,

Department of Cardiology, St Thomas' Hospital London SE1 7EH, United Kingdom.

Accepted for publication 12 February 1997
Conclusions-Haemostatic and haemodynamic abnormalities are associated with left atrial thrombus in nonrheumatic atrial fibrillation, and may help stratify thromboembolic risk.

(Heart 1997;77:407-411)

Keywords: atrial fibrillation; thrombosis; transoesophageal echocardiography

Non-rheumatic atrial fibrillation is an established risk factor for stroke. ${ }^{1}$ The nature of the relation between atrial fibrillation and stroke is still not fully understood, but it is likely that in most cases stroke in the presence of atrial fibrillation is due to embolism of left atrial thrombus. Although recent randomised trials have confirmed the benefits of anticoagulation in prevention of stroke in such patients, it has been possible to identify subgroups with high risks of bleeding, ${ }^{2}$ as well as defining high risk groups for thrombosis. Refining the risk profile, for both thrombosis and bleeding, may improve targeting of antithrombotic treatment. Clinical and conventional echocardiographic abnormalities have been identified which stratify embolic stroke risk ${ }^{3}$; further refinement might be accomplished by detection of left atrial thrombus and by better understanding of the mechanisms of left atrial thrombosis. Transoesophageal echocardiography enables the visualisation of left atrial thrombus and the identification of spontaneous echo contrast, a smoke-like echo proposed as a risk marker for thromboembolism. ${ }^{5-7}$ It allows measurement of blood velocity within the left atrium using Doppler ultrasound. Reduced or abnormal blood flow is a plausible risk factor for thrombosis, and is a likely explanation for the increase in relative risk of thrombosis in atrial fibrillation associated with mitral stenosis, ${ }^{1}$ left ventricular dysfunction, or left atrial enlargement. ${ }^{4}$

Certain haemostatic variables can detect thromboembolism within the vasculature, and some haemostatic abnormalities could prove to be additional risk factors for thrombosis. Fibrinogen and von Willebrand factor have been identified as risk factors for stroke. ${ }^{89}$ Haemostatic abnormalities have been noted in patients with atrial fibrillation compared to those in sinus rhythm, ${ }^{10-12}$ and small studies have indicated haemostatic activation in high risk groups, ${ }^{13} 14$ without identifying left atrial thrombus directly.

The aim of this study was therefore to relate measures of left atrial blood flow and haemostatic activity to the presence of left atrial thrombus seen at transoesophageal echocardiography in patients with non-rheumatic atrial fibrillation.

\section{Methods}

SUBJECTS

Between October 1992 and December 1994 109 subjects with non-rheumatic atrial fibrillation were recruited from The General Infirmary and St James's University Hospital, Leeds. The study was approved by the research 
ethics committee of the United Leeds Teaching Hospitals Trust. Cases with evidence of atrial fibrillation on their presenting ECG were recruited consecutively from the inpatient and outpatient departments. The arrhythmia was confirmed at the time of venous blood sampling and at echocardiography. Patients with evidence of sinus rhythm on either of these occasions were documented as having paroxysmal atrial fibrillation (PAF). Subjects were excluded if they had evidence of rheumatic heart disease (history of rheumatic fever, clinical or echocardiographic evidence of mitral stenosis) or had a prosthetic heart valve. Current or recent (less than four weeks) oral anticoagulant or heparin usage, or the presence of underlying conditions likely to affect haemostasis (recent surgery, active infection, inflammation, or malignancy) were exclusion criteria, as was a recent (less than four weeks) thrombotic event, including venous thromboembolism, myocardial infarction, or stroke.

Decisions about subsequent antithrombotic treatment were left to the patients' attending physician.

\section{VENOUS BLOOD SAMPLING}

Samples were taken between 0900 and 1000 after 15 minutes of rest in the semirecumbent position. Venous blood was sampled from the antecubital fossa with a 19G butterfly needle, minimal stasis, and a multiple syringe technique. After discarding the first $5 \mathrm{ml}, 9 \mathrm{ml}$ of blood were sampled into $1 \mathrm{ml}$ of $0 \cdot 1 \mathrm{M}$ sodium citrate at room temperature, $9 \mathrm{ml}$ into $1 \mathrm{ml}$ of cold citrate $\left(4^{\circ} \mathrm{C}\right), 4.5 \mathrm{ml}$ into $0.5 \mathrm{ml}$ of heparin/aprotinin anticoagulant $\left(4^{\circ} \mathrm{C}\right)$ for fibrinopeptide $\mathrm{A}$ estimation, and $4.5 \mathrm{ml}$ into a glass tube containing $0.5 \mathrm{ml}$ of a citrate, adenosine, dipyridamole, and theophylline solution (Diatube $\mathrm{H}, 4^{\circ} \mathrm{C}$ ) (Diagnostica Stago, France) for markers of platelet activation. Within 20 minutes of venepuncture, room temperature samples were centrifuged at $2000 \times g$ for 20 minutes and cold samples at $3000 \times g$ for 30 minutes at $4^{\circ} \mathrm{C}$. The platelet-poor plasma was then snap frozen and stored at $-40^{\circ} \mathrm{C}$ until assayed.

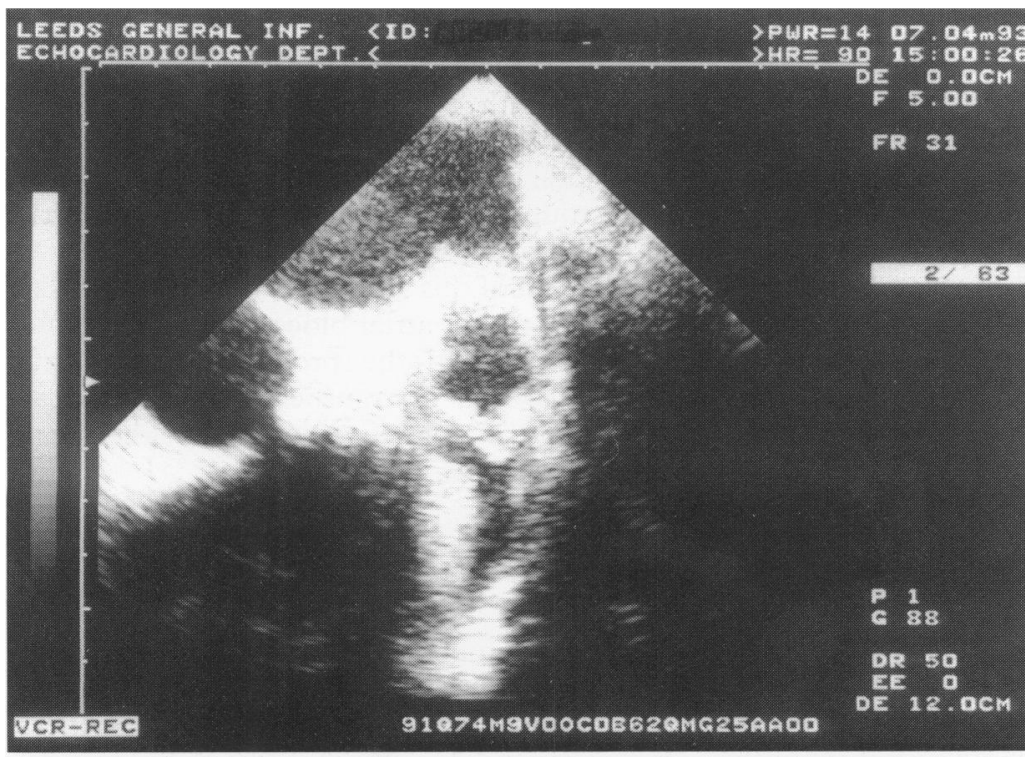

Figure 1 Thrombus seen in the left atrial appendage.

\section{BIOLOGICAL ASSAYS}

The activity of coagulant proteins factor VII (coefficient of variation $(\mathrm{CV})=6.6 \%$ ) and factor VIII ( $\mathrm{CV}=7 \cdot 0 \%$ ) was estimated using the one stage clotting time based assay, and plasma fibrinogen concentration was estimated by the method of Clauss $(\mathrm{CV}=3.5 \%$, normal range in our laboratory (NR) = $1 \cdot 37-3 \cdot 40 \mathrm{~g} / \mathrm{l})$. Von Willebrand factor antigen was quantified by enzyme immunoassay (EIA) (Dako, Copenhagen) according to the supplied manufacturer's instructions $(\mathrm{CV}=$ $4 \cdot 7 \%, \mathrm{NR}=0.86-1 \cdot 18 \mathrm{IU} / \mathrm{ml})$. Markers of platelet activation, $\beta$ thromboglobulin $(\mathrm{CV}=$ $8.0 \%, \mathrm{NR}=10-40 \mathrm{IU} / \mathrm{ml}$ ), and platelet factor $4(\mathrm{PF} 4, \mathrm{CV}=12 \%, \mathrm{NR}=0-5.0 \mathrm{IU} / \mathrm{ml})$ were quantified by EIA using the manufacturer's instructions (Diagnostica Stago). Ddimer concentrations ( $\mathrm{CV}=7 \cdot 4 \%, \mathrm{NR}<$ $400 \mathrm{ng} / \mathrm{ml}$, Diagnostica Stago), and markers of haemostatic activation: thrombin-antithrombin complexes (TAT, $\mathrm{CV}=13 \%, \mathrm{NR}=$ $1 \cdot 0-4 \cdot 1 \mu \mathrm{g} / 1$, Behringwerke, Marburg), prothrombin fragment $1+2(\mathrm{~F} 1+2, \mathrm{CV}=8.6 \%$, $\mathrm{NR}=0 \cdot 44-1 \cdot 1 \mathrm{nmol} / 1$, Behringwerke), and fibrinopeptide A (FPA, CV $=12 \%, \mathrm{NR}$ $<3 \mathrm{ng} / \mathrm{ml}$, Diagnostica Stago) were assayed using EIA according to instructions supplied.

\section{TRANSOESOPHAGEAL ECHOCARDIOGRAPHY}

Transoesophageal echocardiography was attempted in 109 subjects using a Toshiba $5 \mathrm{MHz}$ single plane probe or a Vingmed $5 \mathrm{MHz}$ multiplane probe. Images were analysed on-line by two observers (RMH and either KEB or JMM) for the presence of left atrial thrombus and spontaneous echo contrast. Thrombus was defined as a discrete echodensity, visible in more than one plane, of $>5 \mathrm{~mm}$ diameter and acoustically distinct from underlying endocardium (fig 1). Spontaneous echo contrast was defined as a swirling non-homogeneous echo seen in the left atrium and distinguishable from background noise or speckle by manipulation of gain settings (fig 2). Differences between observers were resolved by consensus; if observers could not agree, the feature was deemed not to be present.

Pulsed wave Doppler ultrasound was used to estimate peak blood velocity at three sites within the left atrium: the mouth of the left atrial appendage directed towards the probe, the mid-left atrium (mid-LA) toward the mitral valve orifice, and a point $5 \mathrm{~mm}$ on the left atrial side of the mitral leaflet co-apt point directed through the valve (MV outflow). For each site, pulsed wave Doppler spectra were recorded on videotape for off-line analysis. Peak velocities were measured for 5-10 cardiac cycles at each site, and averaged to overcome beat to beat variation.

\section{ANALYSIS}

Univariate analyses were performed between patients with and without thrombus, using unpaired $t$ tests on haemodynamic variables, Mann-Whitney tests for haemostatic variables, and $\chi^{2}$ tests with Yates' correction for categorical variables. A multiple logistic regression 


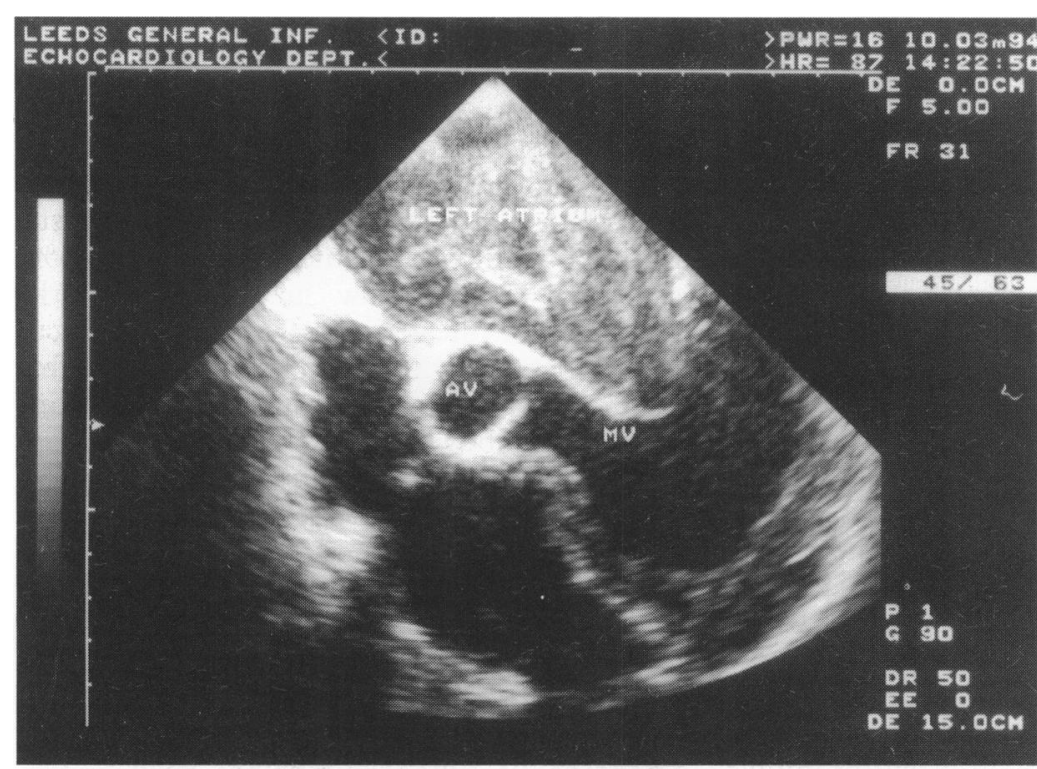

Figure 2 Spontaneous echo contrast in the left atrium. AV, atrial valve; $M V$, mitral valve.

model was constructed using a stepwise technique, including all variables with univariate $P$ $<0 \cdot 1$. Analyses were performed using SPSS $6 \cdot 1$ for Windows.

Table 1 Clinical characteristics of study patients

\begin{tabular}{lcc}
\hline & \multicolumn{2}{l}{ Left atrial thrombus } \\
\cline { 2 - 3 } & Present & Absent \\
\hline Subjects & 19 & 88 \\
Women (\%) & $6(32)$ & $32(36)$ \\
Men (\%) & $13(68)$ & $56(64)$ \\
Mean (SD) age (years) & $73 \cdot 0(10 \cdot 4)$ & $68 \cdot 6(9 \cdot 1)$ \\
Hypertension (\%) & $9(47)$ & $38(43)$ \\
Ischaemic heart disease (\%) & $9(47)$ & $31(35)$ \\
PAF (\%) & $1(5 \cdot 3)$ & $13(15)$ \\
Smokers (\%) & $3(16)$ & $20(23)$ \\
Previous CVA (\%) & $3(16)$ & $44(50)$ \\
Aspirin use (\%) & $10(53)$ & \\
\hline
\end{tabular}

PAF, paroxysmal atrial fibrillation; CVA, cerebrovascular accident.

Table 2 Mean peak velocity (SD) at three sites in the left atrium

\begin{tabular}{lll}
\hline & \multicolumn{2}{l}{ Left atrial thrombus } \\
\cline { 2 - 3 } Site & Present & Absent \\
\hline LAA outflow $(\mathrm{m} / \mathrm{s})$ & $0 \cdot 17(0 \cdot 07)^{\star}$ & $0 \cdot 26(0 \cdot 12)$ \\
Mid-LA $(\mathrm{m} / \mathrm{s})$ & $0 \cdot 23(0 \cdot 10)$ & $0 \cdot 28(0 \cdot 11)$ \\
MV outflow $(\mathrm{m} / \mathrm{s})$ & $0 \cdot 39(0 \cdot 12)$ & $0 \cdot 46(0 \cdot 14)$ \\
\hline
\end{tabular}

LAA, left atrial appendage; LA, left atrium; MV, mitral valve.

${ }^{\star} \mathrm{P}<0.001 v$ absent group.

Table 3 Median (interquartile range) values for haemostatic variables studied

\begin{tabular}{|c|c|c|}
\hline & \multicolumn{2}{|l|}{ Left atrial thrombus } \\
\hline & Present & Absent \\
\hline \multicolumn{3}{|l|}{ Platelet activation } \\
\hline$\beta$ thromboglobulin $(\mathrm{IU} / \mathrm{ml})$ & $56 \cdot 8(44 \cdot 1$ to $77 \cdot 6) \ddagger$ & $30.4(24.5$ to 43.9$)$ \\
\hline \multirow{2}{*}{\multicolumn{3}{|c|}{ Haemostatic activation }} \\
\hline & & \\
\hline Thrombin-antithrombin complex $(\mu \mathrm{g} / \mathrm{ml})$ & $5.59(3.90$ to 6.93$) \ddagger$ & $3.06(2.06$ to 4.81$)$ \\
\hline Prothrombin fragment $1+2(\mathrm{nM} / \mathrm{ml})$ & $1.58(1.19$ to 2.46$)$ & $1.33(1.09$ to 1.87$)$ \\
\hline Fibrinopeptide A (ng/ml) & $3 \cdot 14(2 \cdot 22$ to $8 \cdot 22)$ & $2.44(1.56$ to 4.04$)$ \\
\hline \multicolumn{3}{|l|}{ Coagulant proteins } \\
\hline von Willebrand factor (IU/ml) & $1.81(1.4 \text { to } 2 \cdot 8)^{\star}$ & $1.52(1.18$ to 2.08$)$ \\
\hline Factor VII:C (IU $/ \mathrm{ml})$ & $0.91(0.73$ to 1.09$)$ & $0.91(0.80$ to 1.17$)$ \\
\hline Factor VIII:C (IU/ml) & $2.05(1.64$ to 2.64$)$ & $1.96(1.51$ to 2.34$)$ \\
\hline Fibrinogen $(g / 1)$ & $3.64(3.05$ to 4.55$)$ & $3.40(2 \cdot 82$ to $4 \cdot 24)$ \\
\hline \multicolumn{3}{|l|}{ Fibrin turnover } \\
\hline D-dimer (ng/ml) & 479 (334 to 738$) \dagger$ & 298 (175 to 502$)$ \\
\hline
\end{tabular}

$\ddagger \mathrm{P}<0.001,+\mathrm{P}<0.01,{ }^{\star} \mathrm{P}<0.05 v$ absent group.

\section{Results}

The left atrium and left atrial appendage were visualised adequately in 107 of 109 patients. In one subject the probe could not be advanced because of an unrecognised pharyngeal pouch; in one other, inadequate views of the left atrial appendage were obtained. Left atrial thrombus was identified in 19 patients $(18 \%)$. Eighteen patients had thrombus in the left atrial appendage only; one had thrombus in the left atrial appendage and in the body of the left atrium.

Spontaneous echo contrast was present in some part of the left atrium in $67(63 \%)$ patients; of the 19 with left atrial thrombus, 16 had spontaneous echo contrast $(84 \%)\left(\chi^{2}=\right.$ 3.55, $\mathrm{P}=0 \cdot 06$ ).

Clinical characteristics of patients with and without left atrial thrombus are shown in table 1. There were no significant differences between the groups, although patients with thrombus tended to be older than those without (73 (10) $v 69$ (9) years; $P=0.07$ ).

Table 2 shows the mean (SD) peak velocities at three sites in the left atrium for patients with and without thrombus. Peak left atrial appendage outflow velocity was significantly lower in the thrombus group $(0.17(0.07) \mathrm{m} / \mathrm{s} v$ $0.26(0.12) \mathrm{m} / \mathrm{s} ; \mathrm{P}<0.0001)$.

Table 3 shows the median values and interquartile ranges for the haemostatic variables measured. Markers of platelet activation, $\beta$ thromboglobulin $(P<0.0001)$ and platelet factor $4(P=0.007)$ were raised in the thrombus group, as were thrombin-antithrombin complexes $(P=0.0007)$ and $D$-dimers $(P=$ $0.004)$, indicating activation of coagulation and accelerated fibrin turnover. von Willebrand factor antigen titres were also higher in the thrombus group $(P=0.02)$, without a corresponding increase in factor VIII:C. Plasma fibrinogen concentrations did not differ significantly between the two groups.

With the exception of an overall reduction in $\beta$ thromboglobulin concentrations (31 v $37.2 \mathrm{IU} / \mathrm{ml} ; \mathrm{P}=0.04)$, aspirin use was not associated with significant differences in the haemostatic variables studied. Figure 3 shows significantly higher $\beta$ thromboglobulin concentration in thrombus patients, whether taking aspirin or not.

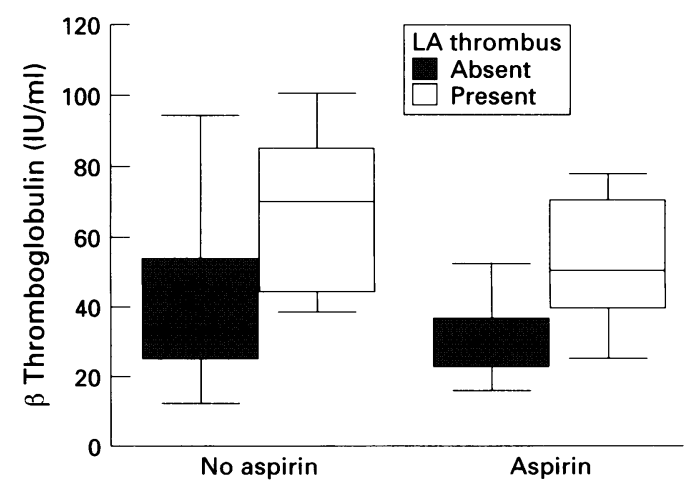

Figure 3 Boxplot of median (interquartile range) $\beta$ thromboglobulin concentrations in patients with and without left atrial (LA) thrombus, according to aspirin use. 
Table 4 Independent correlates of left atrial thrombus

\begin{tabular}{lcl}
\hline Variable & $R^{*}$ & $P$ \\
\hline Peak LAA velocity & -0.25 & 0.001 \\
$\beta$ thromboglobulin & $0 \cdot 23$ & 0.002 \\
von Willebrand factor & 0.13 & 0.04 \\
Age & 0 & n.s. \\
SEC & 0 & n.s. \\
\hline
\end{tabular}

LAA, left atrial appendage; SEC, spontaneous echo contrast. $\star$ Partial correlation coefficient.

A multiple logistic regression model was developed to define the variables most strongly associated with the presence of left atrial thrombus, including age as a possible confounding variable. Table 4 shows the partial correlation coefficients and significance levels for the variables most strongly identified with left atrial thrombus. Reduced left atrial appendage velocity, raised $\beta$ thromboglobulin, and raised von Willebrand factor antigen were independent correlates of left atrial thrombus; there was no independent relation with age or spontaneous echo contrast.

\section{Discussion}

The value of haemostatic and haemodynamic abnormalities in predicting future stroke is not directly addressed by this case-control study. Subjects without visible thrombus may have had previous thromboembolism, or be at risk of future events. We can, however, be reasonably sure that those in the left atrial thrombus group did have left atrial thrombosis. Transoesophageal echocardiography can detect left atrial thrombus with a high degree of accuracy, ${ }^{1516}$ with recently reported sensitivity and specificity of $100 \%$ and $99 \%$, respectively using a two observer technique compared with direct inspection at operation. ${ }^{17}$ Our thrombus detection rate of $18 \%$ is in line with other series of cases of nonrheumatic atrial fibrillation. ${ }^{18-20}$ The initial use of a single plane probe may have reduced the sensitivity for detection of left atrial thrombus; however, all thrombi detected using the multiplane probe were visible in single plane mode.

There were no differences in the prevalence of previous stroke, ischaemic heart disease, hypertension, or smoking between patients with thrombi and those without; it is therefore unlikely that these account for the haemostatic differences observed. Likewise, use of aspirin was distributed evenly between the groups; this affected overall concentrations of $\beta$ thromboglobulin alone, but not the differences noted between patients with and without thrombi. While patients with paroxysmal atrial fibrillation may show less evidence of haemostatic activation than their chronic counterparts, ${ }^{21}$ the prevalence of this arrhythmia was not significantly different between the two groups. Patients with thrombus tended to be older than those without; age, however, was not independently associated with left atrial thrombus.

Virchow identified a triad of components implicated in the process of thrombosis ${ }^{22}$ : abnormal conditions of blood flow, vessel wall damage, and abnormal blood constituents. In this study we examined variables relating to all three components of the triad. The loss of atrial systole in atrial fibrillation and the increased relative risk of stroke associated with rheumatic atrial fibrillation point strongly towards a role for stasis of blood in left atrial thrombosis. Previous studies have associated abnormal blood flow in the left atrial appendage with atrial fibrillation, ${ }^{2324}$ particularly in patients with mitral stenosis, ${ }^{23}$ or with a history of presumed cardioembolism. ${ }^{25}$ Left atrial thrombus has been correlated with reduced left atrial appendage velocities, ${ }^{23} 25$ increased left atrial and left atrial appendage size, ${ }^{24}{ }^{26}$ and the presence of spontaneous echo contrast. ${ }^{5618}$ Our data support the correlation of reduced left atrial appendage velocity with left atrial thrombus, and suggest that this measure is a more powerful risk marker for thrombosis than spontaneous echo contrast. Spontaneous echo contrast has been associated with reduction in velocities elsewhere in the left atrium ${ }^{27}$; we suggest that some measure of left atrial appendage blood flow is more likely to contribute to the risk of predominantly left atrial appendage thrombosis in nonrheumatic atrial fibrillation.

Independent of the reductions in blood velocity, we found evidence suggesting that endothelial dysfunction and haemostatic activation are associated with left atrial thrombosis. von Willebrand factor is released from damaged endothelium, and has a role in platelet aggregation through a receptor on the platelet surface. Previous studies have shown raised plasma von Willebrand factor in subjects with atrial fibrillation compared to controls in sinus rhythm, ${ }^{1011}$ with a suggestion of higher levels in patients with enlarged left atria. von Willebrand factor is released during platelet aggregation, and its concentration in the peripheral circulation is increased in a variety of conditions associated with vascular injury; it may therefore be a reflection of platelet activation occurring in left atrial thrombosis, or a marker of local (endocardial) or widespread endothelial damage.

We found further evidence that platelet activation, with raised concentrations of platelet factor 4 , and in particular $\beta$ thromboglobulin, was associated with left atrial thrombus. Concentrations of both these variables are raised in subjects with atrial fibrillation compared to controls in sinus rhythm ${ }^{10}$; two previous studies showed raised concentrations of $\beta$ thromboglobulin in ischaemic stroke patients. ${ }^{28} 29$

In general, other studies in patients with atrial fibrillation have shown similar coagulation abnormalities to those observed in ours when compared with controls in sinus rhythm. With the exception of fibrinogen, we have found that such abnormalities are greatest in the group of non-rheumatic patients with atrial fibrillation who are shown to have left atrial thrombosis. We found no differences in plasma fibrinogen: concentrations in the two groups were comparable to those in the atrial fibrillation group of Lip et al. ${ }^{11}$ We did, however, find evidence of increased thrombin gen- 
eration and fibrin turnover in subjects with thrombus.

Haemostatic changes have been found in a wide variety of thrombotic disorders, including stroke, ${ }^{9}$ ischaemic heart disease, ${ }^{30}$ and venous thromboembolism. ${ }^{31}$ Furthermore, baseline abnormalities of such variables as fibrinogen, ${ }^{832}$ and fibrin $\mathrm{D}$-dimer may have a predictive value even if the relation is not causal. $^{3334}$ The relation between haemostatic abnormalities and left atrial thrombosis is unclear; increases in markers of platelet and haemostatic activation suggest a reflection of thrombosis rather than a causal role. These circulating haemostatic markers may have a role in generating further thrombosis. Whether these markers are generated in the left atrium is not known, although one study during balloon valvoplasty has indicated abnormalities of haemostasis in blood sampled from the left atrium. ${ }^{14}$ It may be that peripheral sampling underestimates the degree of haemostatic activation in left atrial thrombosis because of haemodilution.

Detection of left atrial thrombosis, and better understanding of its formation, should be beneficial in stratifying risk of stroke for the individual with atrial fibrillation. This study indicates that, in particular, left atrial appendage peak velocity and markers of platelet or haemostatic activation show promise as indicators of thromboembolic risk in non-rheumatic atrial fibrillation.

The study was supported by a grant from the Stroke Association.

1 Wolf PA, Abbott RD, Kannel WB. Atrial-fibrillation as an independent risk factor for stroke: the Framingham Study. Stroke 1991;22:983-8.

2 Stroke Prevention in Atrial Fibrillation Investigators. Warfarin versus aspirin for prevention of thromboembolism in atrial fibrillation: stroke prevention in atrial fibbolism in atrial fibrillation: stroke prevention
rillation II Study. Lancet 1994;343:687-91.

3 Stroke Prevention in Atrial Fibrillation Investigators. Predictors of thromboembolism in atrial fibrillation. I. Clinical features of patients at risk. Ann Intern Med 1992; 116:1-5.

4 Stroke Prevention in Atrial Fibrillation Investigators. Predictors of thromboembolism in atrial fibrillation. II Echocardiographic features of patients at risk. Ann Intern Med 1992;116:6-12

5 Daniel W, Nellessen U, Schroder E, Nonnast-Daniel B, Bednarski P, Nikutta P, et al. Left atrial spontaneous echo contrast in mitral valve disease: an indicator for an increased thromboembolic risk. $\mathcal{F}$ Am Coll Cardiol 1988 11:1204-11

6 Black IW, Hopkins AP, Lee LCL, Walsh WF. Left atrial spontaneous echo contrast: a clinical and echocardiographic analysis. F Am Coll Cardiol 1991;18:398-404.

7 Leung DY, Black IW, Cranney GB, Hopkins AP, Walsh WK. Prognostic implications of left atrial spontaneous echo contrast in non-valvular atrial fibrillation. $\mathcal{\exists} \mathrm{Am}$ Coll Cardiol 1994;24:755-62.

8 Wilhelmsen L, Svardsudd K, Korsan-Bengtsen R, Larsson B, Welin L, Tibblin G. Fibrinogen as a risk factor for stroke and myocardial infarction. $N$ Engl $\mathcal{F}$ Med 1984; 311:501-5.

9 Uchiyama S, Takeuchi M, Osawa M, Kobayashi I, Maruyama S, Aosaki M, et al. Platelet function tests in Maruyama S, Aosaki $M$, et al. Platelet function tests in
thrombotic cerebrovascular disorders. Stroke 1983;14: 511-16.

10 Gustafsson C, Blomback M, Britton M, Hamsten A, Svensson J. Coagulation factors and the increased risk of stroke in nonvalvular atrial fibrillation. Stroke 1990;21 47-51.

11 Lip GYH, Lowe GDO, Rumley A, Dunn FG. Increased markers of thrombogenesis in chronic atrial fibrillation:
effects of warfarin treatment. Br Heart f 1995;73:527-33.
12 Kumagai K, Fukunami $M$, Ohmori $M$, Kitabatake A, Kamada T, Hoki N. Increased intracardiovascular clotting in patients with chronic atrial fibrillation. $7 \mathrm{Am} \mathrm{Coll}$ Cardiol 1990;16:377-80.

13 Asakura H, Hifumi S, Jokaji H, Saito M, Kumabashiri I, Uotani C, et al. Prothrombin fragment F1+2 and thrombin-antithrombin complex are useful markers of the hypercoagulable state in atrial fibrillation. Blood Coagul Fibrinolysis 1992;3:469-73.

14 Yamamoto $\mathrm{K}$, Ikeda U, Seino $\mathrm{Y}$, Mito $\mathrm{H}$, Fujikawa $\mathrm{H}$, Sekiguchi $\mathrm{H}$, et al. Coagulation activity is increased in the
left atrium of patients with mitral stenosis. $f \mathrm{Am}$ Coll left atrium of patients
Cardiol 1995;25:107-12.

15 Aschenberg W, Schluter M, Kremer P, Schroder E, Siglow $\mathrm{V}$, Bleifeld W. Transesophageal two-dimensional echocardiography for the detection of left atrial appendage cardiography for the detection of left atrial
thrombus. $\mathcal{F}$ Am Coll Cardiol 1986;7:163-6.

16 Acar J, Cormier B, Grimberg D, Kawthekar G, Iung B Scheuer B, et al. Diagnosis of left atrial thrombi in mitra stenosis-usefulness of ultrasound techniques compared with other methods. Eur Heart $\mathcal{f} 1991$;12 (suppl B): 70-6.

17 Manning WM, Waksmonski C, Haering JM, Weintraub RM, Rooney PS, Maslow AS, et al. Sensitivity and specificity of transesophageal echo for left atrial thrombi: a prospective surgical study [abstract]. Circulation 1994; 90(suppl I):I-224.

18 Fatkin D, Kelly RP, Feneley MP. Relations between left atrial appendage blood flow velocity, spontaneous ech contrast and thromboembolic risk in vivo. $\mathrm{f} \mathrm{Am} \mathrm{Coll}$ Cardiol 1994;23:961-9.

19 Manning WJ, Silverman DJ, Keighley CS, Oettgen P, Douglas PS. Transesophageal echocardiographically facilitated early cardioversion using short-term anticoagulation: final resultsof a prospective 4.5 year study. $\mathcal{F} \mathrm{Am}$ Coll Cardiol 1995;25:1354-6.

20 Krauss D, Balasia B, Sandelski J, Marcus R, Lang R. Predictors of atrial thrombus detectable by transesophageal echocardiography in nonrheumatic atrial fibesophageal echocardiography in nonrheumatic atrial fib-
rillation [abstract]. Circulation 1994;90(suppl I):I-224.

21 Lip GY, Lowe GD, Rumley A, Dunn FG. Fibrinogen and fibrin D-dimer levels in paroxysmal atrial fibrillation: evidence for intermediate levels of intravascular thrombogenesis. Am Heart f 1996;131:724-30.

22 Virchow R. Gesammelte abhandlungen zur Wissenschaftlichen Medtzin. Frankfurt: Medinger Sohn, 1856:219-732.

23 Suetsugu M, Matsuzaki M, Toma Y, Anno Y, Maeda T, Okada T, et al. Detection of mural thrombi and analysis of blood flow velocities in the left atrial appendage using transesophageal two-dimensional echocardiography and pulsed Doppler flowmetry. $\mathcal{F}$ Cardiol 1988;18:385-98.

24 Pollick C, Taylor D. Assessment of left atrial appendage function by transesophageal echocardiography. Circulation 1991;84:223-31.

25 Verhorst PMJ, Kamp O, Visser CA, Verheugt FWA. Left atrial appendage flow velocity assessment using transesophageal echocardiography in nonrheumatic atrial fibrillation and systemic embolism. Am f Cardiol 1993;71: 192-6.

26 Rubin DN, Keighley CS, Riley MF, Katz SE, Cutlip CA Manning WJ. Left atrial anatomy and appendage function identify patients with new atrial fibrillation and atrial thrombi [abstract]. Circulation 1994;90(suppl I):I-225.

27 Siostrzonek P, Koppensteiner R, Gossinger H, Zanganeh ostrzonek P, Koppensteiner R, Gossinger H, Zangane $M$, Heinz G, Kreiner G, et al. Hemodynamic and hemorrheologic determinants of left atrial spontaneous ech pathic dilated cardiomyopathy. Am Heart $\mathcal{F}$ 1993;125: pathic 4 .

28 Taomoto K, Asada M, Kanazawa Y, Matsumoto S. Usefulness of the measurement of plasma $\beta$-thromboglobulin $(\beta-\mathrm{TG})$ in cerebrovascular disease. Stroke 1983;14: $518-24$

29 Shah AB, Beamer N, Coull BM. Enhanced in vivo platelet activation in subtypes of ischemic stroke. Stroke 1985 16:643-7.

30 Thompson SG, Kienast J, Pyke SDM, Haverkate F, van de Loo JCW. Haemostatic factors and the risk of myocardia infarction or sudden death in patients with angina pectoris. N Engl F Med 1995;332:635-41.

31 Boneu B, Bes G, Pelzer H, Sie P, Boccalon H. D-dimers, thrombin-antithrombin III complexes and prothrombin fragmenfs $1+2$ : diagnostic value in clinically suspected deep vein thrombosis. Throm Haemost 1991;65:28-32.

32 Meade TW, Mellows S, Brozovic M, Miller GJ, Chakrabarti RR, North WRS, et al. Haemostatic function and ischaemic heart disease: principal results of the Northwick Park Heart Study. Lancet 1986;ii:533-7.

33 Fowkes FGR, Lowe GDO, Housley E, Rattray A, Rumley A, Elton RA, et al. Cross-linked fibrin degradation prodA, Elton RA, et al. Cross-linked fibrin degradation products, progression of peripheral vascular disease,
of coronary heart diseae. Lancet 1993;342:84-6.

of coronary heart diseae. Lancet 1993;342:84-6.
34 Ridker PM, Hennekens CH, Cerskus A, Stampfer MJ. Plasma concentration of cross-linked fibrin degradation product (D-dimer) and risk of future myocardial infarction among apparently healthy men. Circulation 1994;90 2236-40. 